\title{
Mapping spectroscopic uncertainties into prospective methane retrieval errors from Sentinel-5 and its precursor
}

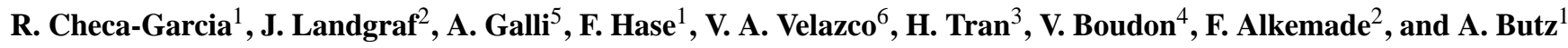 \\ ${ }^{1}$ IMK-ASF, Karlsruhe Institute of Technology (KIT), Karlsruhe, Germany \\ ${ }^{2}$ Netherlands Institute for Space Research (SRON), Utrecht, the Netherlands \\ ${ }^{3}$ Laboratoire Interuniversitaire des Systèmes Atmosphériques, CNRS-UMR 7583, Université Paris Est Créteil, \\ Université Paris Diderot, Institut Pierre-Simon Laplace, France \\ ${ }^{4}$ Laboratoire Interdisciplinaire Carnot de Bourgogne, UMR6303 CNRS-Univ. Bourgogne Franche-Comté, \\ 9 Av. A. Savary, BP 47870, Dijon, France \\ ${ }^{5}$ Space Research and Planetary Sciences, Physics Institute, University of Bern, Bern, Switzerland \\ ${ }^{6}$ Center for Atmospheric Chemistry, Faculty of Science, Medicine \& Health, University of Wollongong, \\ Wollongong, Australia
}

Correspondence to: R. Checa-Garcia (ramiro.garcia@kit.edu, r.checagarcia@gmail.com)

Received: 2 December 2014 - Published in Atmos. Meas. Tech. Discuss.: 29 January 2015

Revised: 10 July 2015 - Accepted: 6 August 2015 - Published: 8 September 2015

\begin{abstract}
Sentinel-5 (S5) and its precursor (S5P) are future European satellite missions aiming at global monitoring of methane $\left(\mathrm{CH}_{4}\right)$ column-average dry air mole fractions $\left(\mathrm{XCH}_{4}\right)$. The spectrometers to be deployed onboard the satellites record spectra of sunlight backscattered from the Earth's surface and atmosphere. In particular, they exploit $\mathrm{CH}_{4}$ absorption in the shortwave infrared spectral range around $1.65 \mu \mathrm{m}$ (S5 only) and $2.35 \mu \mathrm{m}$ (both S5 and S5P) wavelength. Given an accuracy goal of better than $2 \%$ for $\mathrm{XCH}_{4}$ to be delivered on regional scales, assessment and reduction of potential sources of systematic error such as spectroscopic uncertainties is crucial. Here, we investigate how spectroscopic errors propagate into retrieval errors on the global scale. To this end, absorption spectra of a groundbased Fourier transform spectrometer (FTS) operating at very high spectral resolution serve as estimate for the quality of the spectroscopic parameters. Feeding the FTS fitting residuals as a perturbation into a global ensemble of simulated S5- and S5P-like spectra at relatively low spectral resolution, $\mathrm{XCH}_{4}$ retrieval errors exceed $0.6 \%$ in large parts of the world and show systematic correlations on regional scales, calling for improved spectroscopic parameters.
\end{abstract}

\section{Introduction}

The greenhouse gas methane $\left(\mathrm{CH}_{4}\right)$ plays a key role in anthropogenically driven climate change (Kirschke et al., 2013). Therefore, monitoring of atmospheric $\mathrm{CH}_{4}$ abundances is one of the crucial elements of future Earth observing satellite missions (e.g., Streets et al., 2013). The European Space Agency (ESA) and its national partners have scheduled the Sentinel-5 Precursor (S5P), also known as TROPOMI (Veefkind et al., 2012), and the Sentinel-5 (S5) (Ingmann et al., 2012) for launch in 2016 and around 2021, respectively. Both satellites carry spectrometers sensitive to the shortwave infrared (SWIR) spectral range. $\mathrm{CH}_{4}$ absorption in sunlight backscattered from the Earth's surface and atmosphere allows for the retrieval of column-average dry air mole fractions of methane $\left(\mathrm{XCH}_{4}\right)$. Thereby, the S5P and S5 strategy builds on the pioneering heritage of the SCanning Imaging Absorption spectroMeter for Atmospheric CHartographY (SCIAMACHY) (Bovensmann et al., 1999) and the Greenhouse Gases Observing Satellite (GOSAT) (Kuze et al., 2009) demonstrating that highly accurate satellite remote sensing of $\mathrm{XCH}_{4}$ (e.g., Frankenberg et al., 2005; Schneising et al., 2009; Butz et al., 2011; Palmer et al., 2011) can be a valuable tool to gain insight into $\mathrm{CH}_{4}$ emissions at the Earth's surface (e.g., Bergamaschi et al., 2007). 
Estimating such surface-atmosphere fluxes through inverse modeling, however, poses stringent accuracy requirements on the retrieved $\mathrm{XCH}_{4}$. Regionally or temporally correlated biases as low as $1 \%$ can jeopardize the usefulness of the $\mathrm{XCH}_{4}$ satellite records for inverse modeling of surface fluxes (Bergamaschi et al., 2007, 2009). An analogue, potentially even more stringent requirement applies to remote sensing of column-average dry air mole fractions of carbon dioxide $\left(\mathrm{XCO}_{2}\right)$ (e.g., Miller et al., 2007; Chevallier et al., 2007; Basu et al., 2013). Therefore, considerable effort is dedicated to estimating and reducing sources of error for $\mathrm{XCH}_{4}$ (and $\mathrm{XCO}_{2}$ ) retrievals from solar backscatter measurements. Most studies focus on how to avoid or evaluate errors due to light-path uncertainties in light-scattering atmospheres (e.g., Frankenberg et al., 2005; Oshchepkov et al., 2008; Butz et al., 2009, 2010; Reuter et al., 2010; O'Dell et al., 2012; Buchwitz et al., 2013). In particular, Butz et al. (2012) assess the residual aerosol- and cirrusinduced $\mathrm{XCH}_{4}$ retrieval errors for an S5P-like observer using a global and seasonal ensemble of simulated S5P measurements. Frankenberg et al. (2008a) demonstrate the detrimental impact of spectroscopic uncertainties on $\mathrm{XCH}_{4}$ retrievals and on the respective surface flux estimates from SCIAMACHY. They find about $20 \%$ overestimation of the tropical $\mathrm{CH}_{4}$ source (up to $60 \mathrm{ppb}$ ) due to a spurious spectroscopic interference between $\mathrm{CH}_{4}$ and water vapor $\left(\mathrm{H}_{2} \mathrm{O}\right)$ absorption in the $1.65 \mu \mathrm{mCH}_{4}$ band. In a previous support study for the S5P mission, Galli et al. (2012) degrade high-resolution spectra around $2.35 \mu \mathrm{m}$ wavelength recorded by ground-based Fourier transform spectrometers (FTS) at a midlatitude and a tropical site to the spectral resolution of the S5P instrument. They conclude on a weak dependence of the retrieved $\mathrm{XCH}_{4}$ on spectral resolution and $\mathrm{H}_{2} \mathrm{O}$ content of the atmosphere pointing at relatively little impact of erroneous spectroscopy on $\mathrm{XCH}_{4}$ retrievals. The spectral fitting residuals in the $2.35 \mu \mathrm{m}$ band, however, reveal a clearly systematic pattern, which is in particular correlated with $\mathrm{H}_{2} \mathrm{O}$ absorption lines.

Here, we aim at mapping spectroscopic errors into $\mathrm{XCH}_{4}$ retrieval errors for an S5- and S5P-like observer on the global scale in order to assess whether error patterns are significant in magnitude and whether they are correlated among regional spatial and seasonal temporal scales. Such correlations are particularly detrimental for surface flux inversions since they can be readily mistaken for a regional or seasonal flux pattern, unlike random noise errors that cancel themselves out on the aggregated scales. To this end, the global ensemble of simulated measurements used previously by Butz et al. (2012) is revisited by replacing the light-path perturbation through a perturbation due to imperfect spectroscopy. Thereby the spectroscopic perturbation is estimated from fitting residuals to observations of a direct-sun viewing, ground-based Fourier transform spectrometer (FTS) operating at very high spectral resolution. Submitting the perturbed satellite spectra to the retrieval algorithm (which is not aware of the perturbation) allows for assessing the residual $\mathrm{XCH}_{4}$ forward model error due to imperfect spectroscopy.

This paper is organized as follows. Section 2 describes the retrieval algorithm and the general properties of the S5P and S5 trial ensemble. Section 3 describes the ground-based FTS measurements and introduces the method - and its assumptions - to generate a spectroscopic perturbation among the satellite trial ensemble. Section 4 discusses the spectroscopyinduced $\mathrm{XCH}_{4}$ retrieval errors, and Sect. 5 concludes the study.

\section{Satellite retrieval and trial ensemble}

Remote sensing of atmospheric parameters in general requires a forward model $\boldsymbol{F}$ that relates the retrieval parameters included in the state $\boldsymbol{x}$ (with $x_{j}$ the $j$ th retrieval parameter) with the measurements $\boldsymbol{y}$ (with $y_{i}$ the $i$ th spectral element):

$\boldsymbol{y}=\boldsymbol{F}(\boldsymbol{x})+\boldsymbol{\epsilon}_{y}+\boldsymbol{\epsilon}_{\mathrm{F}}$,

with $\boldsymbol{\epsilon}_{y}$ the noise error due to detector noise (for example) and $\boldsymbol{\epsilon}_{\mathrm{F}}$ the forward model error due to approximate description of the relevant physics or due to errors of parameters feeding $\boldsymbol{F}$ (for example). Here, we intentionally introduce a well-defined spectroscopy-related forward model error $\epsilon_{\mathrm{F}}$ as described in Sect. 3.

The simulated measurements $\boldsymbol{y}$ are spectra of backscattered sunlight in the SWIR spectral range. Thereby, instrument properties are implemented according to the S5 instrument characteristics summarized in Table 1. S5 covers spectral bands from the UV to the SWIR (Ingmann et al., 2012) but here, we focus on the SWIR bands around $1.6 \mu \mathrm{m}$ (named henceforth SWIR1) and $2.3 \mu \mathrm{m}$ (named henceforward SWIR3; in the early phase of the mission, SWIR2 had been assigned to a channel around $2.0 \mu \mathrm{m}$, which was dropped later). The finite spectral resolution of the spectrometers is modeled by a Gaussian instrument response function (ISRF) with $0.24 \mathrm{~nm}$ width (full width at half maximum (FWHM)). Measurement noise is calculated from a parametric model that considers both signal-dependent contributions such as photoelectron shot-noise and signal-independent contributions such as dark-current noise. The typical signal to noise ratio (SNR) is on the order of several hundreds for the SWIR bands. Being S5's precursor, S5P features similar instrument characteristics but does not include of the SWIR1 channel around $1.6 \mu \mathrm{m}$.

The forward model $\boldsymbol{F}(\mathbf{x})$ employed here is a variant of the "RemoTeC" algorithm similar to the method used in (Butz et al., 2012). RemoTeC is designed to retrieve $\mathrm{XCH}_{4}$ (and $\mathrm{XCO}_{2}$ ) for solar backscatter spectra in the SWIR spectral range such as collected by GOSAT, the Orbiting Carbon Observatory (OCO-2), S5P and S5. In its standard setup, the algorithm is able to simulate backscattered radiances in particle-loaded atmospheres taking into account light-path modification by scattering. Here, we focus on the evaluation 
Table 1. Characteristics of simulated measurements and retrieval simulations. We investigate three retrieval configurations (SW1, SW3, and SW1+3) that take into account the possible combinations of band SWIR1 and SWIR3. For each channel, the signal to noise ratio (SNR) is modeled according to $\mathrm{SNR}=a R / \sqrt{a R+b}$ with $R$ the backscattered radiance in units [photons $\cdot \mathrm{s}^{-1} \mathrm{~cm}^{-2} \mathrm{sr}^{-1} \mathrm{~nm}^{-1}$ ] and empirical parameters $a$ and $b$ (included on the Table as SNR-a and SNR-b). The full width at half maximum (FWHM) defines the width of the Gaussian instrument response function which is sampled by 2.65 pixels for each band.

\begin{tabular}{|c|c|c|c|c|c|c|c|c|c|}
\hline Name & $\begin{array}{l}\text { Used spectral } \\
\text { range }[\mathrm{nm}]\end{array}$ & $\begin{array}{l}\text { Used spectral } \\
\text { range }\left[\mathrm{cm}^{-1}\right]\end{array}$ & $\begin{array}{l}\text { Target } \\
\text { absorbers }\end{array}$ & SW1 & SW3 & $\mathrm{SW}-1+3$ & SNR-a & SNR-b & FWHM \\
\hline SWIR1 & $\begin{array}{l}\text { 1610-1675 } \\
\quad \text { (divided in }\end{array}$ & $\begin{array}{r}5970-6300 \\
\text { Jo windows) }\end{array}$ & $\mathrm{CH}_{4}, \mathrm{CO}_{2}, \mathrm{H}_{2} \mathrm{O}$ & $\checkmark$ & & $\checkmark$ & $2.132 \times 10^{-7}$ & 414578 & $0.24 \mathrm{~nm}$ \\
\hline SWIR3 & $2305-2385$ & $4200-4325$ & $\mathrm{CH}_{4}, \mathrm{CO}$ & & $\checkmark$ & $\checkmark$ & $2.141 \times 10^{-7}$ & 248836 & $0.24 \mathrm{~nm}$ \\
\hline
\end{tabular}

of spectroscopic errors. Therefore, our study uses a variant of RemoTeC that neglects scattering by aerosols and particles, and the measured spectrum depends only on the absorption properties of the target and interfering absorbers described in Table 1. The estimation of those absorption properties relies on HITRAN-2008 spectroscopic parameters (Rothman et al., 2009) assuming a Voigt line shape. For the water vapor on the SWIR3, the line list described on the reference (Scheepmaker et al., 2013) is used. It should be noticed, however, that for line-shape parameters of $\mathrm{CH}_{4}$ and $\mathrm{H}_{2} \mathrm{O}$ in the SWIR1 and SWIR3 regions, data in HITRAN-2008 and HITRAN-2012 (Rothman et al., 2013) have significant uncertainty because only a subset of the absorption lines was accurately measured or calculated. We refer to (Rothman et al., 2013) for a detailed description. Neglecting refined line-shape effects (line mixing, speed dependence and Dicke narrowing) could also lead to gas retrieval errors (Frankenberg et al., 2008b; Tran et al., 2010; Ghysels et al., 2014). Furthermore, the SWIR1 region in HITRAN-2008 and HITRAN-2012 is still not fully characterized, for both line positions and line intensities, compared to other longer wavelength regions (Nikitin et al., 2013; Brown et al., 2013); detailed assignment and lower state energy are not known in many cases affecting line intensity calculations at temperatures other than 296 K. Further experimental and theoretical investigations of this spectral region are presently underway (Tyuterev et al., 2013).

The spectra modeled by RemoTeC are convolved by the satellite's ISRF, and noise is added as described above to simulate S5- and S5P-like measurements. Section 3 explains how an extra error due to spectroscopic deficiencies is generated and added to the measurements.

The ensemble of scenes for which we perform retrieval simulations is the same as the one described in detail by Butz et al. $(2010,2012)$. While our former studies focus on errors induced by aerosol and cirrus scattering, we neglect such effects here; therefore we assume all scenes to be free of scattering particles. The ensemble covers 1 day in each of the following months: January, April, July, and October, respectively, for which we collect atmospheric absorption and surface reflection properties on an $\sim 3^{\circ} \times 3^{\circ}$ latitude $\times$ longitude grid. Surface albedo in SWIR1 and SWIR3 is assembled from the MODIS land albedo product and a database generated from SCIAMACHY's $2350 \mathrm{~nm}$ channel (Schrijver et al., 2009). Meteorological parameters and the abundances of the relevant atmospheric absorbers listed in Table 1 are taken from models (CarbonTracker for $\mathrm{CO}_{2}$ (Peters et al., 2007), TM4 for $\mathrm{CH}_{4}$ and $\mathrm{CO}$ (Meirink et al., 2008), ECHAM5HAM for $\mathrm{H}_{2} \mathrm{O}$, temperature and pressure, Stier et al., 2005).

Given the simulated measurements $\boldsymbol{y}$, RemoTeC uses an inverse method based on Philipps-Tikhonov regularization (e.g., Hansen, 1998) to estimate the state vector $\boldsymbol{x}$ from Eq. (1). The state vector elements are the 12-layer vertical profiles of $\mathrm{CH}_{4}$ (and $\mathrm{CO}_{2}$ partial column concentrations when SWIR1 band is covered), the total column concentrations of the interfering absorbers $\mathrm{H}_{2} \mathrm{O}$, and $\mathrm{CO}$, and surface reflection parameters (per channel). To find $\boldsymbol{x}$, the inverse method minimizes the cost-function $\mathcal{J}$ given by

$\mathcal{J}(\boldsymbol{x})=\left\|\mathbf{S}_{y}^{-1 / 2}(\mathbf{F}(\boldsymbol{x})-\mathbf{y})\right\|^{2}+\gamma\left\|\mathbf{W}\left(\boldsymbol{x}-\boldsymbol{x}_{\mathrm{a}}\right)\right\|^{2}$,

where $\boldsymbol{x}_{\mathrm{a}}$ is the a priori state vector, $\mathbf{S}_{y}$ is the diagonal error covariance matrix, $\mathbf{W}$ is the regularization matrix, and $\gamma$ is the regularization parameter chosen such that it allows for about 1 degree of freedom for the $\mathrm{CH}_{4}$ (and $\mathrm{CO}_{2}$ ) vertical profiles. The regularization matrix $\mathbf{W}=\mathbf{L}^{\mathrm{T}} \mathbf{L}$ is assembled from the discrete first-order difference operator $\mathbf{L}$ for the $\mathrm{CH}_{4}$ (and $\mathrm{CO}_{2}$ ) vertical profiles and vanishes for all other state vector elements.

Once the state vector solution $\hat{\boldsymbol{x}}$ is found it may be written in linear approximation as a combination of the true state $\boldsymbol{x}_{\text {true }}$, the a priori, and the error contributions,

$\hat{\boldsymbol{x}}=\mathbf{A} \boldsymbol{x}_{\text {true }}+(\mathbf{I}-\mathbf{A}) \boldsymbol{x}_{\mathrm{a}}+\mathbf{G} \boldsymbol{\epsilon}_{y}+\mathbf{G} \boldsymbol{\epsilon}_{\mathrm{F}}$,

where $\mathbf{A}$ is the averaging kernel and $\mathbf{G}$ is the contribution or gain matrix (Rodgers, 2000). For our simulations the true state is identical to the a priori $\left(\boldsymbol{x}_{\text {true }}=\boldsymbol{x}_{\mathrm{a}}\right)$ and Eq. (3) reduces to

$\hat{\boldsymbol{x}}=\boldsymbol{x}_{\text {true }}+\mathbf{G} \boldsymbol{\epsilon}_{y}+\mathbf{G} \boldsymbol{\epsilon}_{\mathrm{F}}$.

Defining an operator $\boldsymbol{h}^{\mathrm{T}}$ that selects the $\mathrm{CH}_{4}$ partial columns from the state vector, adds them up and divides by the total 
dry air column yields the retrieved dry air mole fraction

$$
\begin{aligned}
\mathrm{XCH}_{4} & =\boldsymbol{h}^{\mathrm{T}} \hat{\boldsymbol{x}}=\boldsymbol{h}^{\mathrm{T}} \boldsymbol{x}_{\text {true }}+\boldsymbol{h}^{\mathrm{T}} \mathbf{G} \boldsymbol{\epsilon}_{y}+\boldsymbol{h}^{\mathrm{T}} \mathbf{G} \boldsymbol{\epsilon}_{\mathrm{F}} \\
& =c_{\text {true }}+\Delta c_{y}+\Delta c_{\mathrm{F}} .
\end{aligned}
$$

Since the true state ( $\boldsymbol{x}_{\text {true }}$ and $\left.c_{\text {true }}\right)$ and the noise realization $\left(\epsilon_{y}\right.$ and $\left.\Delta c_{y}\right)$ are known, we can evaluate the targeted $\mathrm{XCH}_{4}$ forward model error $\Delta c_{\mathrm{F}}$ by retrieving $\mathrm{XCH}_{4}$ from the simulated measurements and subtracting $c_{\text {true }}$ and $\Delta c_{y}$.

\section{Generating forward model errors}

The first step in generating the spectroscopic forward model error for the satellite retrieval simulations is selecting a set of spectra recorded by the ground-based, direct-sun viewing FTS located at the Darwin (Australia) TCCON station and operated by University of Wollongong. The instrument, Bruker 125HR, provides spectral coverage in all absorption bands relevant here (see Table 1). Such ground-based FTS measurements have been used in previous studies for validating other ground-based instruments (Gisi et al., 2012) and for comparisons to satellite retrievals of $\mathrm{XCH}_{4}$ and $\mathrm{XCO}_{2}$ (e.g., Guerlet et al., 2013). The FTS-measured atmospheric transmittance spectra are iteratively fitted by a variant of the RemoTeC algorithm. Essentially, our approach follows the methods and analyses in (Galli et al., 2012). Details can be found there. The approach is conceptually analogous to regularly operated TCCON stations and verified by a comparison between the GFIT algorithm and RemoTeC. The adjusted parameters include the vertical profiles of $\mathrm{CH}_{4}$ and the relevant interfering species such as $\mathrm{H}_{2} \mathrm{O}, \mathrm{CO}_{2}, \mathrm{CO}$, and a background baseline transmittance. Assuming that the residual spectra (difference between the measured and the iteratively adjusted modeled spectrum) are dominated by spectroscopic errors, the residual spectra serve as forward model error perturbation $\epsilon_{\mathrm{F}}$ for the satellite retrieval simulations.

The methodology we introduce here assumes that the perturbation $\Delta \tau$ derived from the FTS residuals is dominated by deficiencies of the employed spectroscopic parameters and models. This assumption appears justified by the use of state-of-the-art instrumentation and retrieval techniques with a proven performance record. Further, the FTS residuals represent only a fraction of the actual spectroscopic errors, i.e., those which cannot be compensated by the free parameters of the FTS fitting routine such as $\mathrm{CH}_{4}$ and $\mathrm{H}_{2} \mathrm{O}$ abundances. In that sense, the estimated perturbation is an optimistic interpretation of spectroscopic errors.

For a ground-based, direct-sun viewing observer in a plane-parallel atmosphere, the monochromatic atmospheric transmittance $T_{\mathrm{gb}}$ recorded can be written,

$T_{\mathrm{gb}}(\tau)=\frac{I_{\mathrm{gb}}(\tau)}{E_{\mathrm{S}}}=\exp \left(-\frac{\tau}{\cos \alpha_{\mathrm{gb}}}\right)$,

where $I_{\mathrm{gb}}$ is the observed radiance, $E_{\mathrm{S}}$ is the solar irradiance at top-of-the-atmosphere, $\alpha_{\mathrm{gb}}$ is the solar zenith angle of the ground-based sounding, and $\tau$ is the molecular absorption optical thickness integrated along the zenith direction (i.e., along the vertical). For simplicity, we neglect scattering processes due to molecules and particles. The processing chain of the ground-based FTS measurements provides a best fit $T_{\mathrm{gb} \text {, mod }}$ to the observed transmittance spectra $T_{\mathrm{gb} \text {, true. The }}$ corresponding mismatch

$\Delta T=T_{\mathrm{gb}, \text { true }}-T_{\mathrm{gb}, \bmod }$

is termed the FTS fitting residual to be used for perturbing our simulated satellite retrievals. Figures 1 and 2 show the FTS measured transmittance $T$ and the fitting residual $\Delta T$. Our study uses 50 different FTS spectra recorded at different humidity conditions (Galli et al., 2012). The FTS operates at very high spectral resolution such that the measured residual $\Delta T$ is approximately equal to the monochromatic residual. Further assuming that the FTS fitting residual is caused by errors in spectroscopic parameters, we can evaluate Eq. (7),

$$
\begin{aligned}
\Delta T & =\exp \left(-\frac{\tau_{\text {true }}}{\cos \alpha_{\mathrm{gb}}}\right)-\exp \left(-\frac{\tau_{\text {mod }}}{\cos \alpha_{\mathrm{gb}}}\right) \\
& =T_{\mathrm{gb}, \bmod }\left[\exp \left(-\frac{\Delta \tau}{\cos \alpha_{\mathrm{gb}}}\right)-1\right],
\end{aligned}
$$

with $\Delta \tau=\tau_{\text {true }}-\tau_{\text {mod. }}$ Thus, given the FTS residual $\Delta T$, the FTS transmittance $T_{\mathrm{gb}}$, mod, and the FTS solar zenith angle $\alpha_{\mathrm{gb}}$, we can calculate a perturbation $\Delta \tau$ of the vertical absorption optical thickness

$\Delta \tau=-\cos \alpha_{\mathrm{gb}} \ln \left(\frac{\Delta T}{T_{\mathrm{gb}, \bmod }}+1\right)$.

In the next step, the perturbation derived from the groundbased spectra needs translation into a perturbation of the satellite observations. In a non-scattering atmosphere, the reflectance $R_{\text {sat }}$ observed from a downward-looking spaceborne observer is given by

$$
\begin{aligned}
R_{\mathrm{sat}}(\tau) & =\frac{I_{\mathrm{sat}}(\tau)}{E_{\mathrm{S}}} \\
& =\frac{A \cos \alpha_{\mathrm{sat}}}{\pi} \exp \left(\frac{\tau}{\cos \alpha_{\mathrm{sat}}}+\frac{\tau}{\cos \theta_{\mathrm{sat}}}\right),
\end{aligned}
$$

where $I_{\text {sat }}$ is the reflected radiance, $A$ is the ground albedo, $\alpha_{\text {sat }}$ is the solar zenith angle and $\theta_{\text {sat }}$ is the satellite viewing zenith angle (assumed $\theta_{\text {sat }}=0^{\circ}$, nadir-viewing in our simulation exercise). Replacing the absorption optical thickness $\tau$ in Eq. (11) by a perturbed optical thickness $\tau_{\text {per }}=\tau_{\text {mod }}+\Delta \tau$ yields the perturbed satellite measurement.

Up to here we assume monochromatic light, but in order to introduce the perturbed satellite measurement in the retrieval algorithm we have to take in account the satellite spectral resolution. Therefore, if the satellite retrieval is not aware of this perturbation, the spectroscopic forward model error $\epsilon_{\mathrm{F}}$ amounts to

$\boldsymbol{\epsilon}_{\mathrm{F}}=\left(R \cdot \mathcal{F}_{\text {sat }}\right)\left(\tau_{\text {per }}\right)-\left(R \cdot \mathcal{F}_{\text {sat }}\right)(\tau)$, 


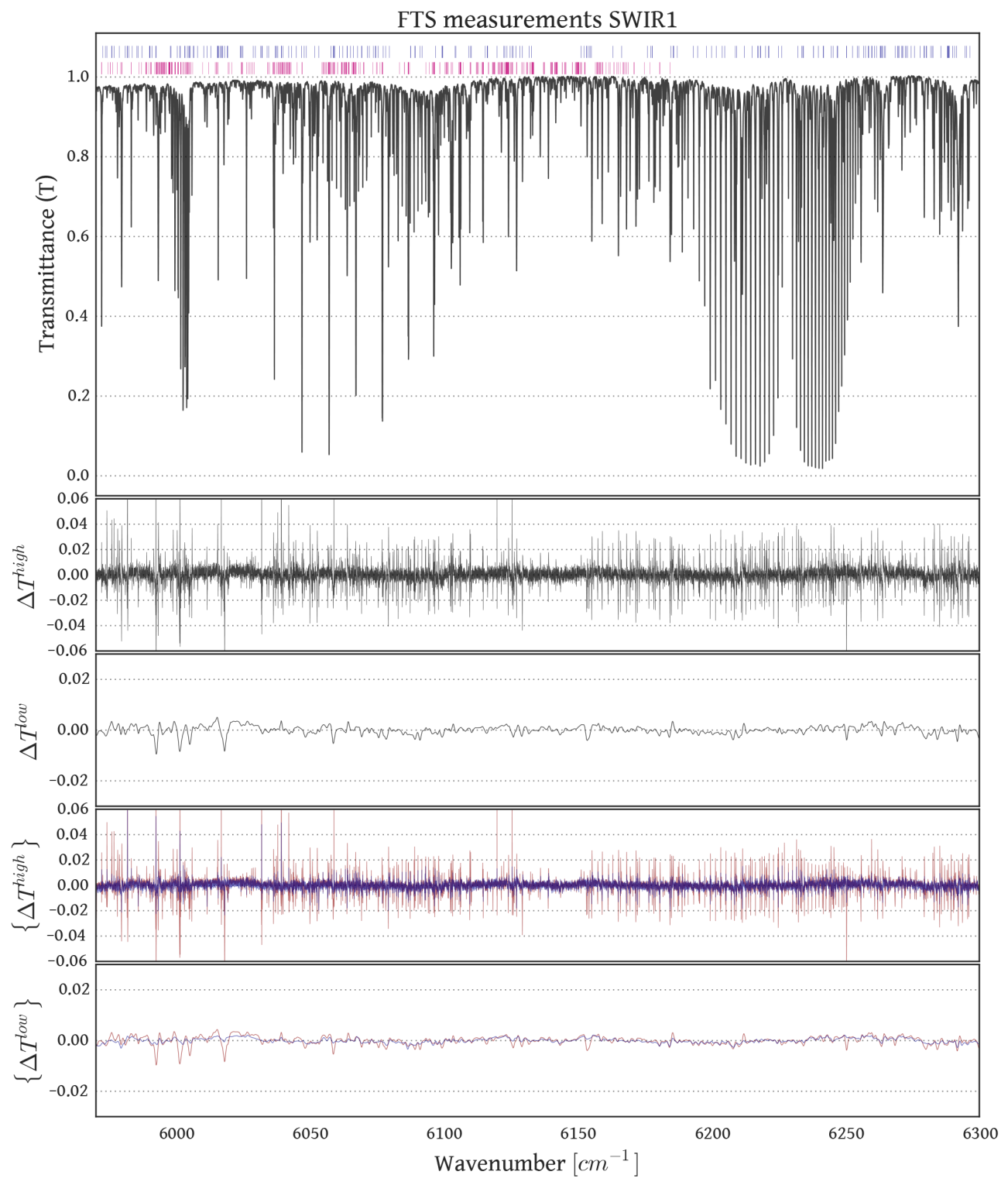

Figure 1. FTS transmittance spectrum in SWIR1 (upper panel), residual transmittance at FTS spectral resolution (first middle panel) and residual transmittance at S5/S5P spectral resolution (second lower panel). The last two panels show the average offour illustrative humid spectra (reddish lines) and four illustrative dry spectra (bluish lines) at FTS and S5/S5P spectral resolutions. The water vapor absorption lines (with line intensity $\geq 10^{-26}\left[\right.$ molec $\left.\mathrm{cm}^{-2}\right]$ ) are shown with blue vertical stacks. The methane absorption lines (with line intensity $\geq 10^{-23}\left[\right.$ molec $\left.\mathrm{cm}^{-2}\right]$ ) are shown with magenta vertical stacks.

where $\left(R \cdot \mathcal{F}_{\text {sat }}\right)$ represents the convolution of the reflectance by the satellite's ISRF $\left(\mathcal{F}_{\text {sat }}\right)$. The forward model error $\epsilon_{\mathrm{F}}$ results in the $\mathrm{XCH}_{4}$ retrieval error $\Delta c_{\mathrm{F}}$ to be evaluated.

Figures 1 and 2 reveal variability in $\Delta \tau$ derived from the two different FTS measurements. Typically, the fitting residuals are larger for wetter than for dryer days. To take into account the dependence on water vapor within the ensemble, the perturbation $\Delta \tau$ for each simulated scene is estimated by interpolating linearly between the perturbations derived from the 50 FTS measurements $\Delta \tau\left(\mathrm{XH}_{2} \mathrm{O}\right)$, where the interpolation variable is the total column water vapor concentration
$\mathrm{XH}_{2} \mathrm{O}$. The effect of the different viewing geometries is implicitly taken into account by attributing the spectroscopic perturbation to the vertical absorption optical thickness. Figures 3 and 4 show how $\mathrm{XH}_{2} \mathrm{O}$ and the air mass factor (AMF) vary among our trial ensemble. AMF for the satellite geometry is defined as

$$
\mathrm{AMF}_{\mathrm{sat}}=\frac{1}{\cos \alpha_{\mathrm{sat}}}+\frac{1}{\cos \theta_{\mathrm{sat}}}=\frac{1}{\cos \alpha_{\mathrm{sat}}}+1,
$$




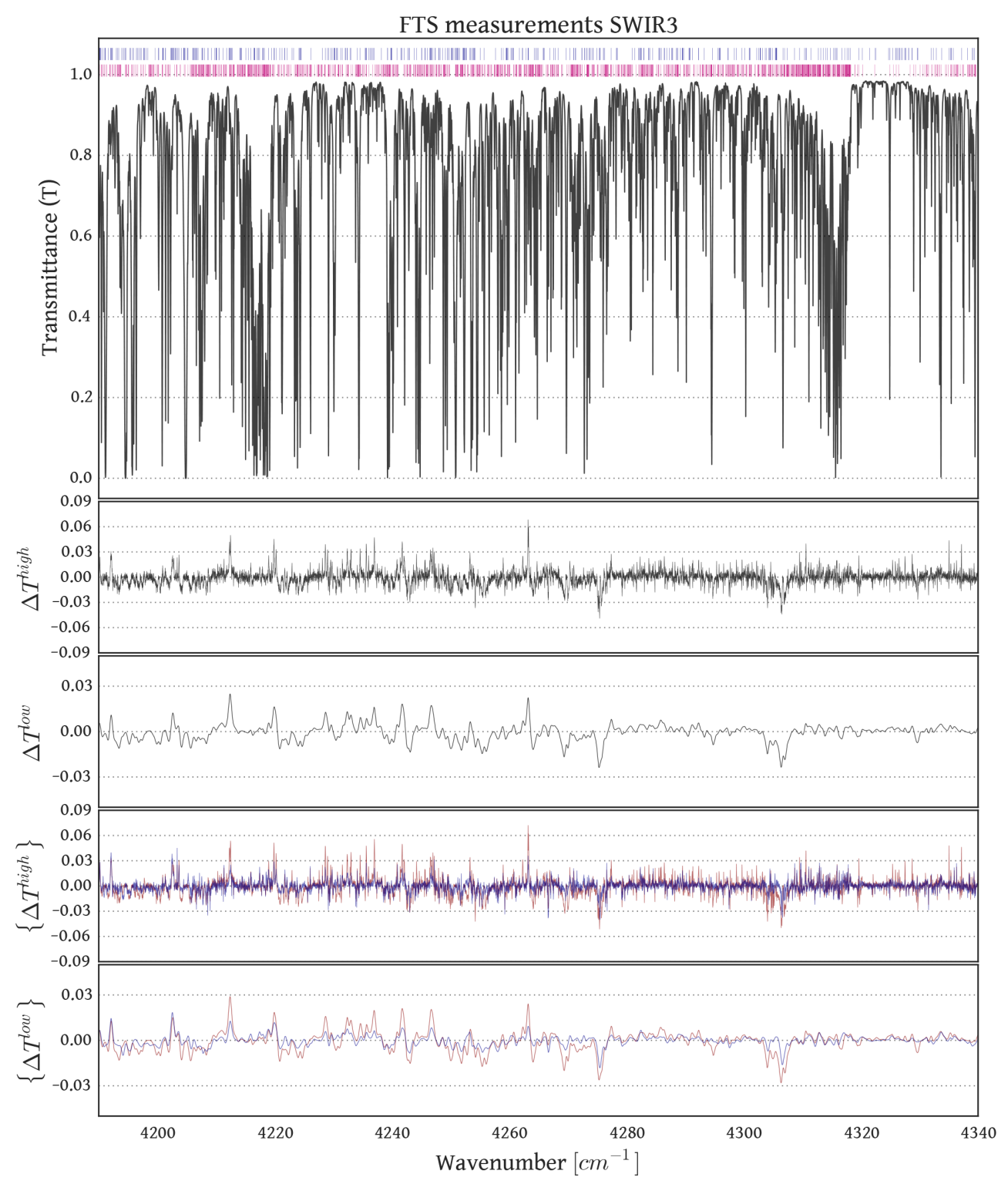

Figure 2. FTS transmittance spectrum in SWIR3 (upper panel), residual transmittance at FTS spectral resolution (first middle panel) and residual transmittance at S5/S5P spectral resolution (second lower panel). The last two panels show the average of four illustrative humid spectra (reddish lines) and four illustrative dry spectra (bluish lines) at FTS and S5/S5P spectral resolutions. The water vapor absorption lines (with line intensity $\geq 10^{-26}\left[\right.$ molec $\left.\mathrm{cm}^{-2}\right]$ ) are shown with blue vertical stacks. The methane absorption lines (with line intensity $\geq 10^{-23}\left[\right.$ molec $\left.\left.\mathrm{cm}^{-2}\right]\right)$ are shown with magenta vertical stacks.

while the AMF for the ground-based FTS measurements is defined as

$\mathrm{AMF}_{\mathrm{gb}}=\frac{1}{\cos \alpha_{\mathrm{gb}}}$.

The satellite soundings are assumed nadir-viewing $\left(\theta_{\mathrm{sat}}=\right.$ $0^{\circ}$ ) with solar zenith angles up to $\alpha_{\text {sat }}=70^{\circ}$, i.e., $\mathrm{AMF}_{\text {sat }}$ ranges between 2 and 3.9. The $\mathrm{XH}_{2} \mathrm{O}$ range covered by the FTS measurements is reasonably large (factor 14 between the low and the high value) that we are confident extrapolating to the actual $\mathrm{XH}_{2} \mathrm{O}$ value of the simulated scene. Dependencies of $\Delta \tau$ on other geophysical variables such as the $\mathrm{CH}_{4}$ and $\mathrm{CO}_{2}$ concentrations are neglected, in particular since these concentrations show comparatively little variability in the atmosphere.

Additionally, three processing steps are carried out. First we determine a small spectral shift between the ground-based and the satellite spectra by comparing the FTS transmittance $T_{\mathrm{gb}}$ to simulated satellite soundings at very high instrument resolution. Second, all the FTS measurements are interpolated to the same spectral grid with a resolution of $0.007 \mathrm{~cm}^{-1}$. Third, to avoid spurious large values of $\Delta \tau$ in 

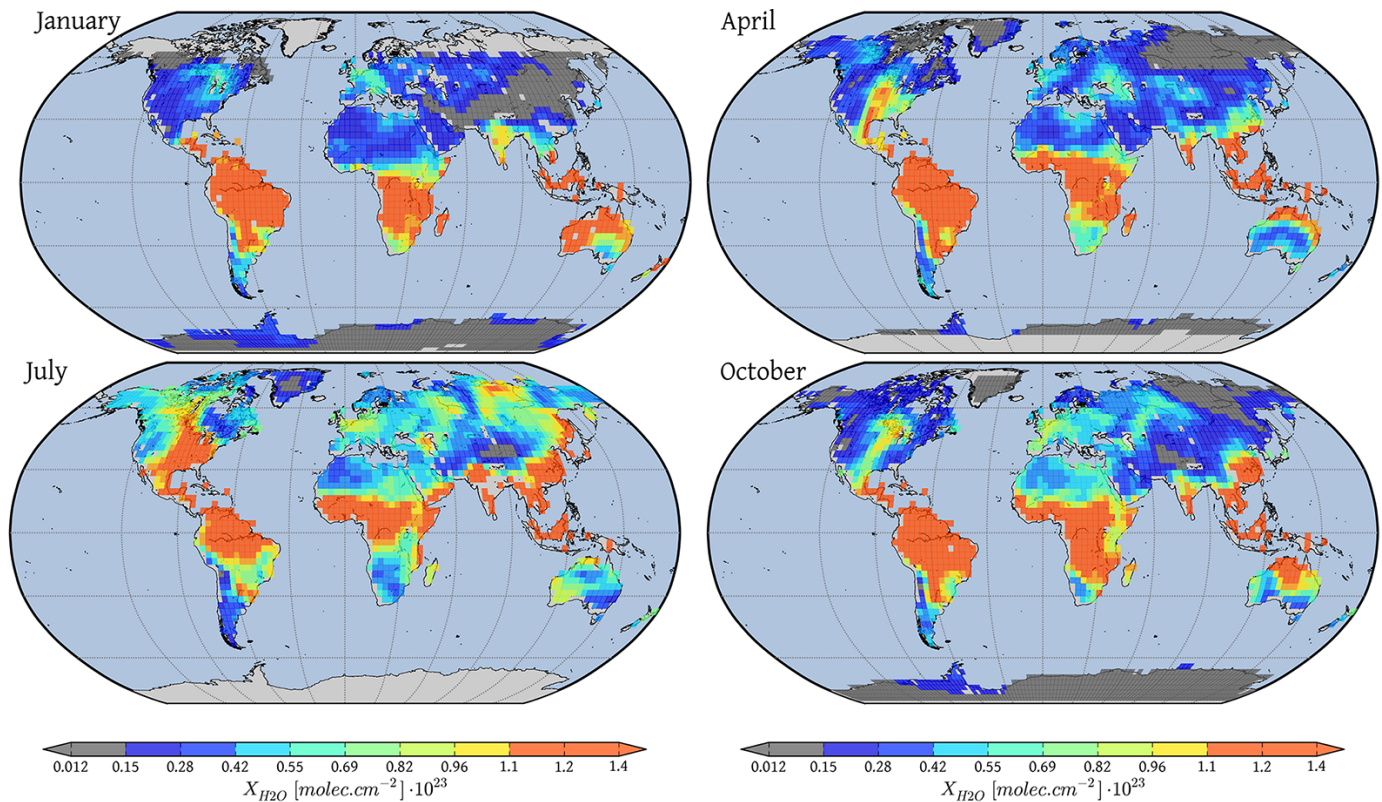

Figure 3. Seasonal $\mathrm{XH}_{2} \mathrm{O}$ concentrations (molecules $\mathrm{cm}^{-2}$ ). Latitudes with solar zenith angles larger than $70^{\circ}$ were filtered.
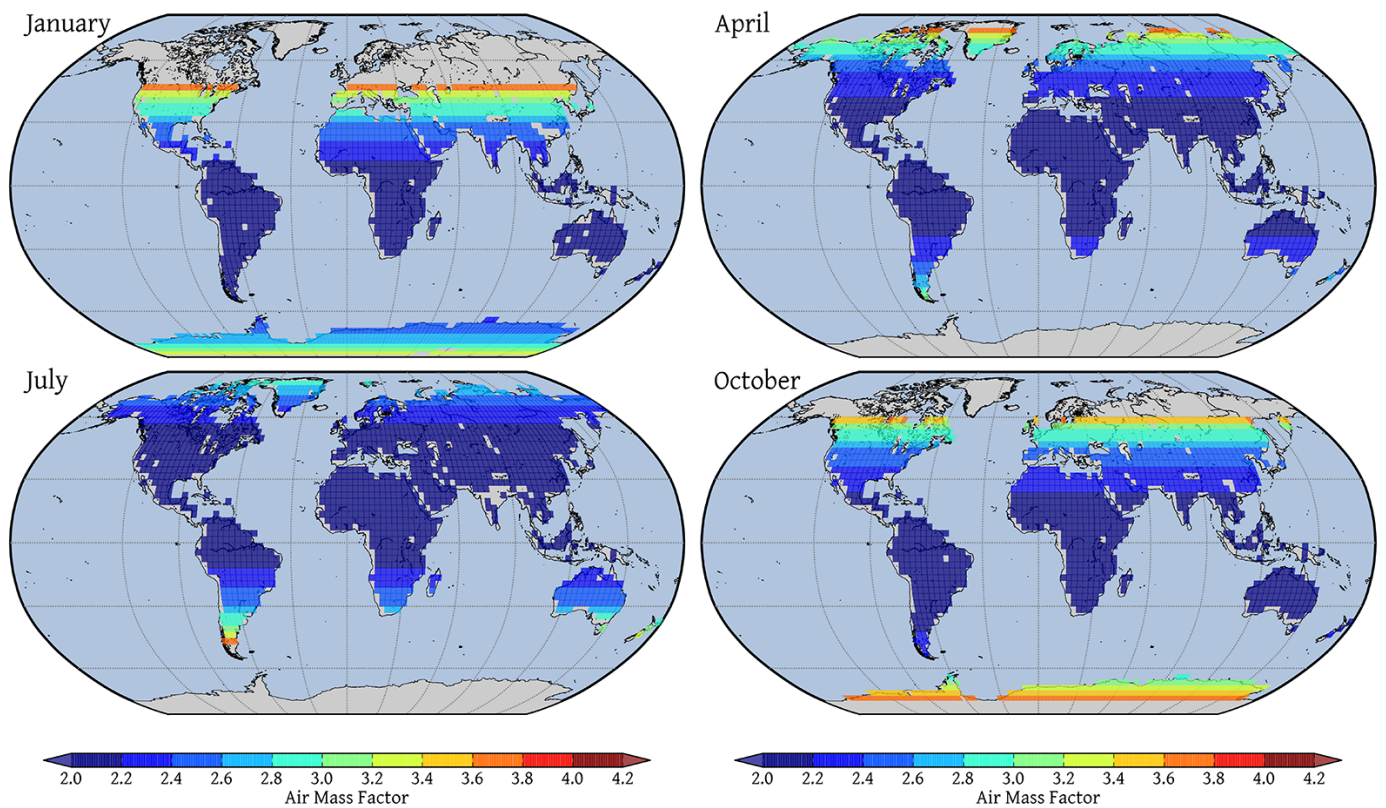

Figure 4. Air mass factor (AMF) for the four months considered. Latitudes with solar zenith angles larger than $70^{\circ}$ were filtered.

the vicinity of optically thick absorption lines $\left(T_{\mathrm{gb}} \rightarrow 0\right.$ in Eq. 9), we adopt a minimum for $T_{\mathrm{gb}}$ equal to the $1-\sigma$ noise level of the FTS spectra.

\section{Spectroscopy-induced $\mathrm{XCH}_{4}$ retrieval errors}

This section discusses the spectroscopic $\mathrm{XCH}_{4}$ retrieval errors $\left(\Delta c_{\mathrm{F}}\right)$ for the three retrieval configurations (SW1, SW3, SW1+3) introduced in Table 1. Thereby, SW3 (covering
SWIR3 only) can be considered representative for the S5P setup, SW1+3 (covering SWIR1 and SWIR3), and SW1 (covering SWIR1 only) are possible strategies for S5. Figures 5 through 7 show the residual $\mathrm{XCH}_{4}$ retrieval errors when introducing the spectroscopic perturbation in our global trial ensemble covering 1 day in each of the following months: January, April, July, and October, respectively. Overall the induced retrieval errors are in the range of a few 

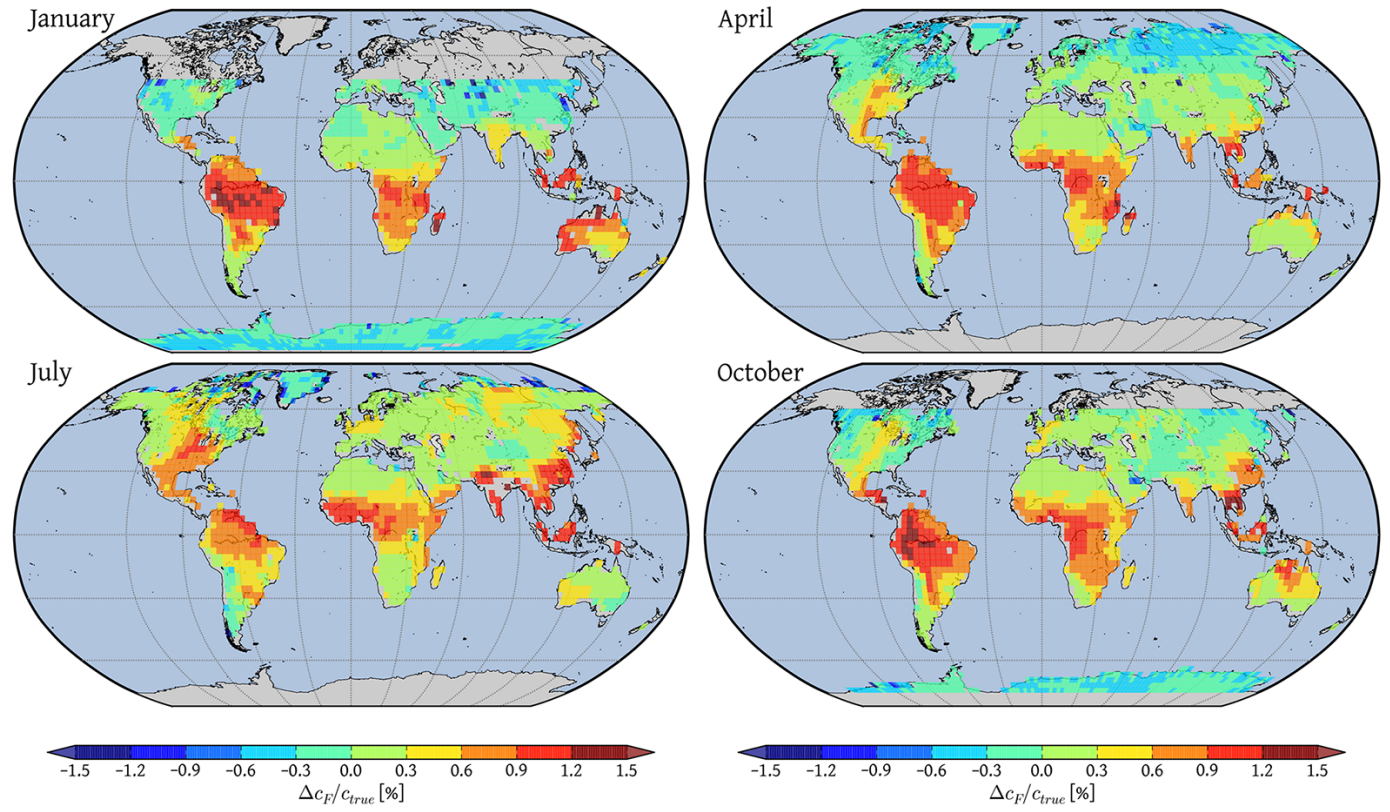

Figure 5. $\mathrm{XCH}_{4}$ retrieval error $\Delta c_{\mathrm{F}} / c_{\text {true }}[\%]$ for retrieval concept SW1 (only SWIR1 band).
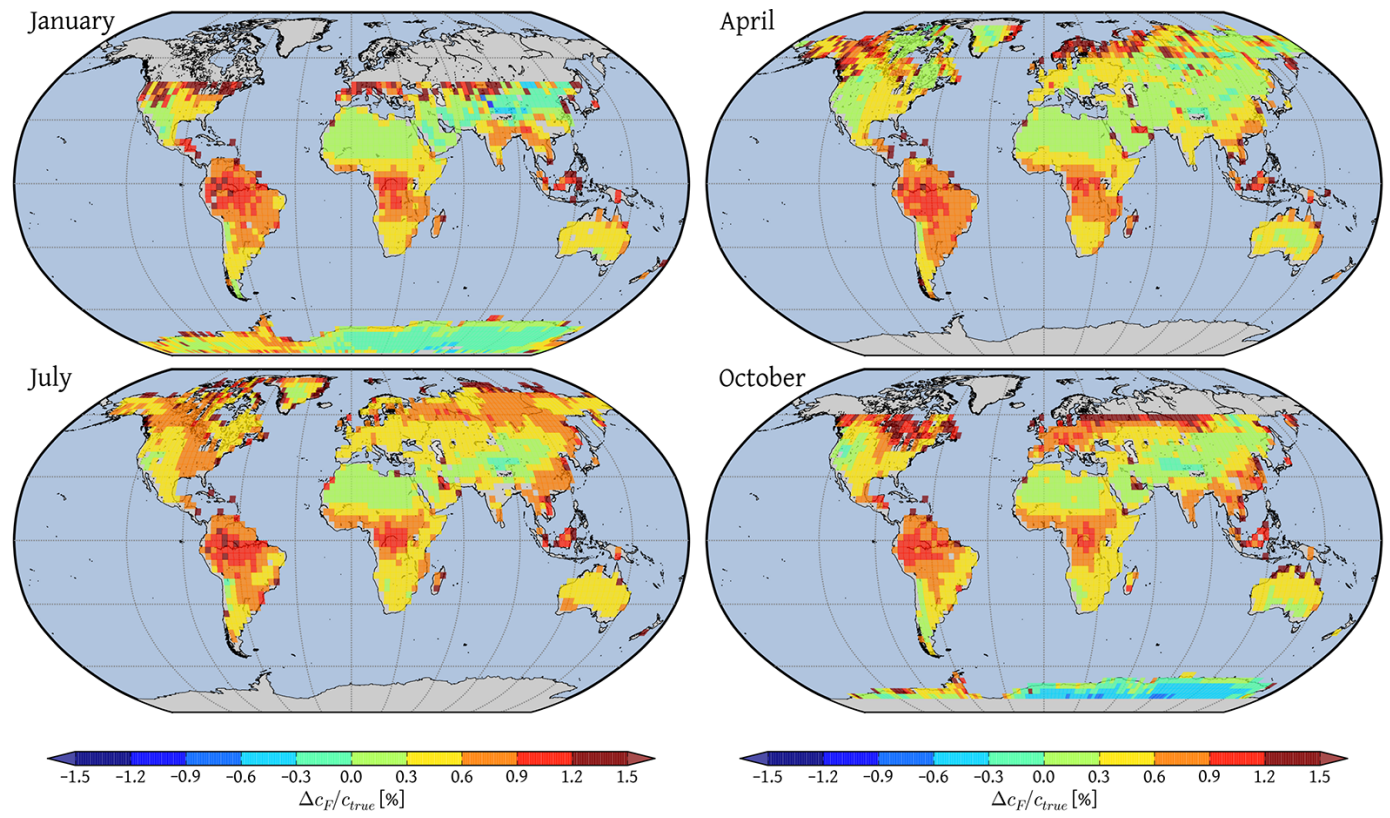

Figure 6. $\mathrm{XCH}_{4}$ retrieval error $\Delta c_{\mathrm{F}} / c_{\text {true }}[\%]$ for retrieval concept SW3 (only SWIR3 band).

tens ppb, which is relevant in the view of S5's and S5P's error budget.

The SW1 configuration (Fig. 5) yields an overall overestimation of the true $\mathrm{XCH}_{4}$ over the tropics, while in midlatitudes it yields slight underestimation. The retrieval errors are consistently around $0.7 \%$ larger in the tropics than in mid-tohigh latitudes, and the latitudinal pattern of the bias persists over all seasons but is less pronounced for July when the sun is high in the sky. The observed latitudinal correlation ap- pears driven by the dependence of the AMF on latitude and season. Similar patterns have been detected in real $\mathrm{XCH}_{4}$ retrievals from SCIAMACHY's SWIR1 band though SCIAMACHY exhibited much coarser spectral resolution than the soundings simulated here. Bergamaschi et al. (2009), for example, assume a latitudinal and monthly bias correction for SCIAMACHY $\mathrm{XCH}_{4}$ to reconcile their source estimates driven by the satellite retrievals and by in situ flask samples. The SW3 configuration (Fig. 6) yields $\mathrm{XCH}_{4}$ errors that are 

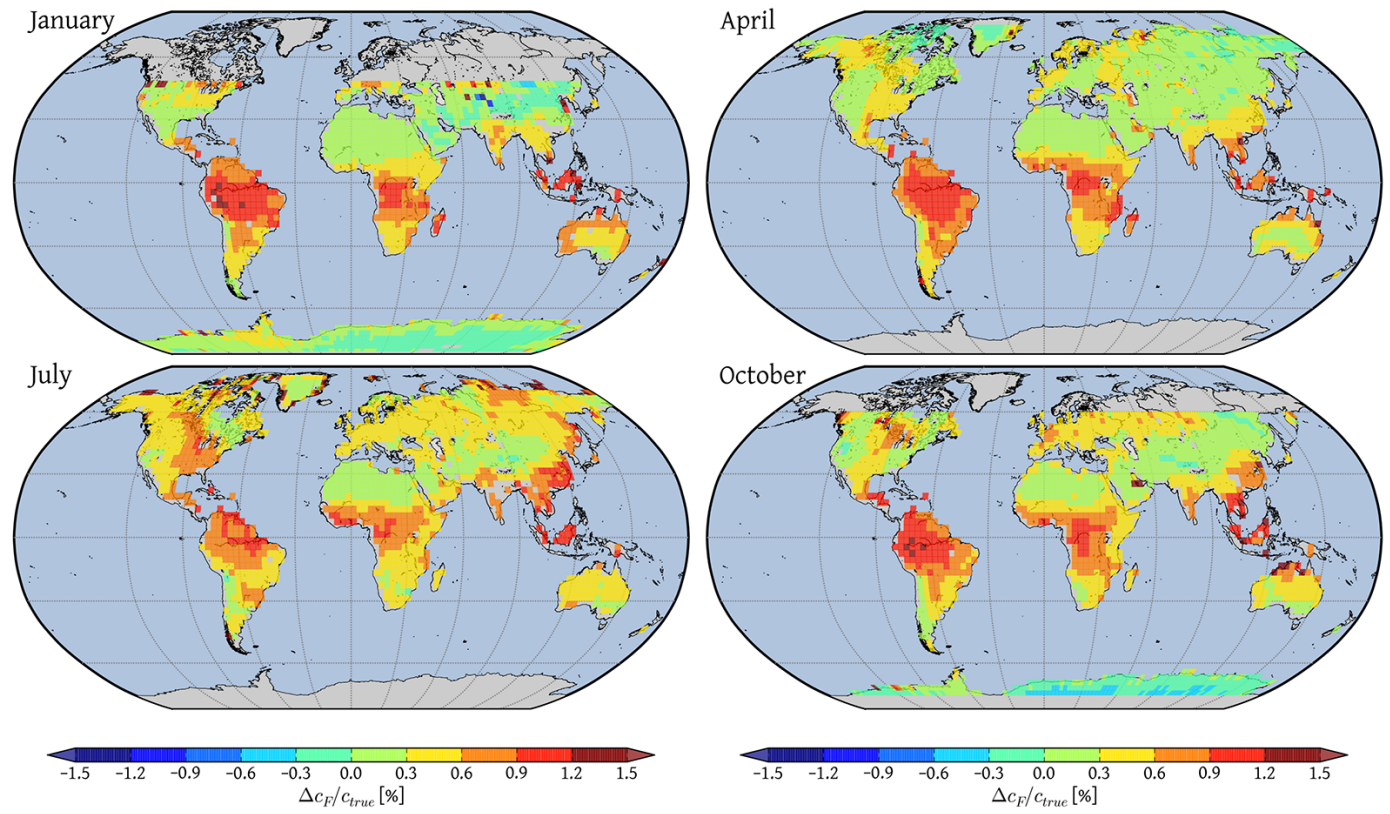

Figure 7. $\mathrm{XCH}_{4}$ retrieval error $\Delta c_{\mathrm{F}} / c_{\text {true }}[\%]$ for retrieval concept SW1+3 (both SWIR1 and SWIR3 bands).

spatially and temporally variable between roughly -0.3 and $1.2 \%$. The error patterns are less correlated with the variation in AMF but tentatively correlate with the variation of total column water vapor $\mathrm{XH}_{2} \mathrm{O}$. Persistently dry scenes such as the desert areas show very small $\mathrm{XCH}_{4}$ errors while the seasonally humid midlatitudes reveal regionally and seasonally variable errors. The tropics, however, show overall small variability of spectroscopy-induced $\mathrm{XCH}_{4}$ errors. The combined configuration SW1+3 (Fig. 7) yields $\mathrm{XCH}_{4}$ error patterns that combine the characteristics observed for SW1 and SW3. The latitudinal dependence of residual errors shows up through a general overestimation of $\mathrm{XCH}_{4}$ in the tropics. In the midlatitudes, a pronounced dependence on the water vapor column overwrites the latitudinal signal.

To illustrate the dependence of the $\mathrm{XCH}_{4}$ errors on $\mathrm{XH}_{2} \mathrm{O}$, Fig. 8 shows the correlation between the simulated errors and the water vapor content of the scene. The correlation confirms the above observation that $\mathrm{SW} 1$ yields $\mathrm{XCH}_{4}$ that is less affected by interference from $\mathrm{XH}_{2} \mathrm{O}$ than $\mathrm{SW} 3$ but still dry scenes over Siberia and humid ones over the tropics correlate with $\mathrm{XCH}_{4}$ errors. SW3 retrievals, however, suffer from a strong interference from water vapor, which results in underestimation of $\mathrm{XCH}_{4}$ for very dry scenes, an increasing overestimation for increasingly humid case and then, a decreasing interference from very humid cases. The complicated structure of overlapping $\mathrm{CH}_{4}$ and $\mathrm{H}_{2} \mathrm{O}$ absorption lines in SWIR3 (Fig. 2) renders such interferences likely. Their detailed mapping on $\mathrm{XCH}_{4}$ retrieval errors, however, largely depends on the choice of the spectral windows and the spectral resolution of the instrument. The $\mathrm{SW} 1+3$ retrievals correlate with water vapor abundances for dry and moderately humid cases but show less dependence on very humid conditions.

These results are consistent with the current status of $\mathrm{CH}_{4}$ and $\mathrm{H}_{2} \mathrm{O}$ spectroscopy in HITRAN-2008/2012. For both SWIR3 and SWIR1, the situation is very challenging for lineshape parameters, namely line broadening. The SWIR3 region being more intense, and given the large number of $\mathrm{CH}_{4}$ and $\mathrm{H}_{2} \mathrm{O}$ lines in this region, satellite retrievals from SWIR3 are more affected by air-broadening errors than retrievals from SWIR1. A second reason that may explain the differences between SWIR1 and SWIR3 is that, for SWIR1, there are dedicated studies providing effective Voigt line-shape parameters (Frankenberg et al., 2008b; Nikitin et al., 2010) which lead to the smaller transmittance residuals shown in Fig. 1 compared to Fig. 2.

\section{Discussion and conclusion}

The goals of Sentinel 5 and the Sentinel 5 Precursor concerning $\mathrm{XCH}_{4}$ retrievals demand a total accuracy better than $2 \%$ (around $30 \mathrm{ppb}$ ) in order to allow for successful source and sink estimates on regional and seasonal scales (Bergamaschi et al., 2009). Uncertainties due to noise are expected to be in the range of $0.1 \%$ (around 2-3 ppb). Forward model errors are present due to imperfect correction of light-path modification driven by particle scattering (Butz et al., 2012). The direct consequence is that additional forward model errors (e.g., due to spectroscopic deficiencies) can jeopardize the desired performance. Our assessment estimates such spectroscopy-induced $\mathrm{XCH}_{4}$ retrieval errors for a global and 

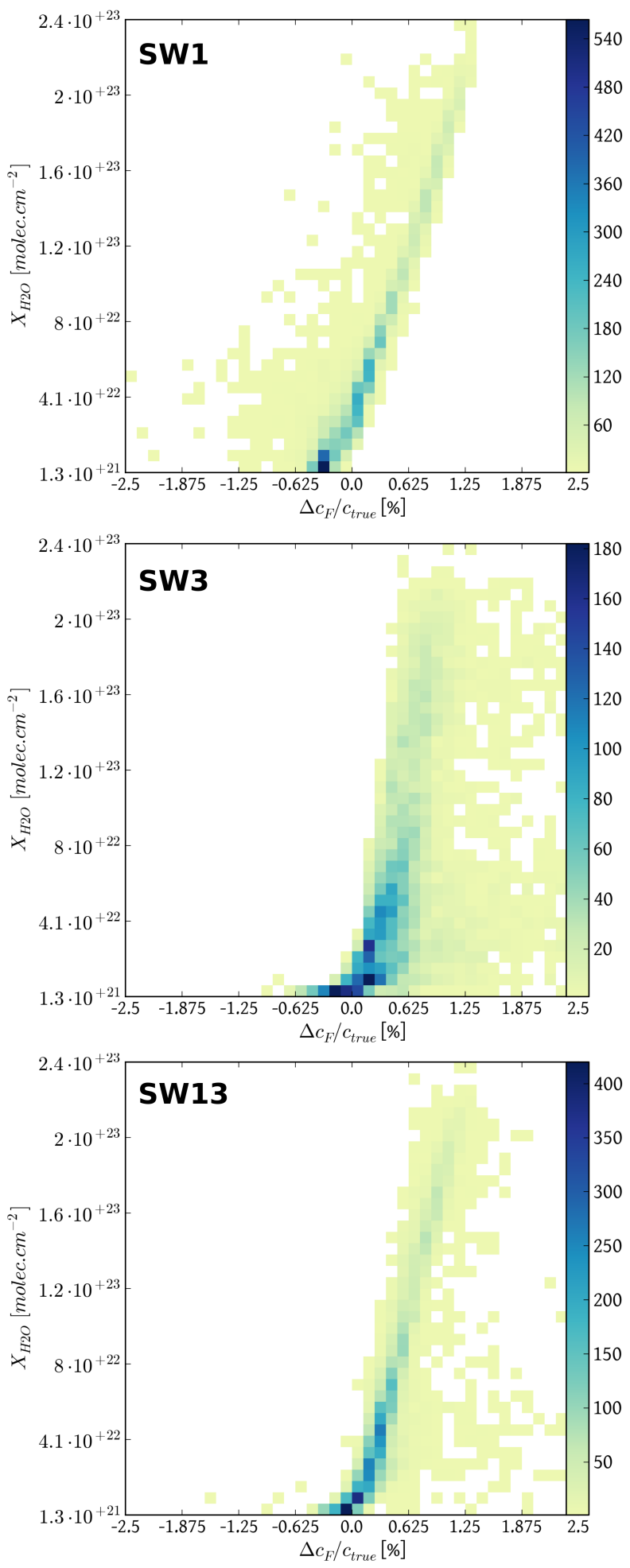

Figure 8. Bi-dimensional histograms of methane retrieval error (\%) with respect to $\mathrm{XH}_{2} \mathrm{O}$ total concentration values. seasonal ensemble of simulated S5- and S5P-like satellite soundings.

The key assumption of our approach is that a realistic spectroscopic perturbation can be derived from spectral fitting residuals of a ground-based, direct-sun viewing FTS. This assumption can be criticized in two ways: (1) the FTS fitting residual contains only that part of the spectroscopic errors that cannot be accounted for through the free parameters of the FTS fit, i.e., only the part of the spectroscopic errors that are in the null-space (Rodgers, 2000) of the FTS retrieval; (2) the fitting residual contains errors due to other sources than spectroscopy. While flaw (1) would generate overly optimistic $\mathrm{XCH}_{4}$ errors, flaw (2) would generate overly pessimistic error patterns or an attribution to the wrong error sources. Since the FTS operates at a spectral resolution that allows for fully resolving the atmospheric absorption lines, we expect flaw (1) to be small. Flaw (2) is battled by using an FTS instrument and data reduction methods with demonstrated state-of-the-art performance. Groundbased FTS records such as those exploited here, have been used in the past to evaluate spectroscopic parameters (e.g., Frankenberg et al., 2008b; Thompson et al., 2012; Scheepmaker et al., 2013).

Translating the ground-based FTS fitting residuals into our satellite sounding ensemble, we consider dependencies on the air mass factor and atmospheric water vapor content but neglect dependencies on other variables such meteorological variables or the $\mathrm{CH}_{4}$ abundance itself. This choice renders parameter space treatable and largely follows previous studies that found water vapor interferences (Frankenberg et al., 2008a; Galli et al., 2012) and latitudinal biases (potentially driven by viewing geometry dependencies) (Bergamaschi et al., 2009) to be the dominating error patterns in $\mathrm{XCH}_{4}$ from space-borne sensors.

However, our study only examines the standard configurations currently foreseen for $\mathrm{CH}_{4}$ retrievals from S5 and S5P. The residual spectroscopic errors found here might be mitigated by selecting narrower spectral windows to avoid spectroscopic interferences. For example, we conducted a sensitivity study that omits the $\mathrm{CH}_{4}$ Q-branch in SWIR-1 from the retrievals. The Q-branch (at about $6005 \mathrm{~cm}^{-1}$ ) consists of a manifold of densely spaced absorption lines that are hard to separate in order to determine spectroscopic parameters and line shapes. Cutting the Q-branch, however, shifts the residual $\mathrm{XCH}_{4}$ errors in the $\mathrm{SW} 1$ configuration to negative values (underestimation), but the range of errors is not reduced substantially. A further strategy to avoid $\mathrm{H}_{2} \mathrm{O}$ absorption interfering with the targeted $\mathrm{CH}_{4}$ lines could be to retrieve the vertical profile of $\mathrm{H}_{2} \mathrm{O}$ instead of the total column. The retrieved $\mathrm{H}_{2} \mathrm{O}$ profile would be unrealistic, but the retrieval would gain freedom to compensate wrong $\mathrm{H}_{2} \mathrm{O}$ spectroscopy by vertical oscillations. Since $\mathrm{H}_{2} \mathrm{O}$ is not the target parameter a wrong $\mathrm{H}_{2} \mathrm{O}$ profile shape would do no harm to S5 and S5P's goal to accurately estimate $\mathrm{CH}_{4}$ concentrations. Since such an as- 
sessment would imply major changes to our inverse method, we defer it to future studies.

Our retrieval simulations indicate that the spectroscopyinduced $\mathrm{XCH}_{4}$ retrieval errors are significant, both in magnitude and in their spatiotemporal correlation structure. While retrievals from the SWIR1 band (SW1) show a moderate correlation with latitude and water vapor, $\mathrm{XCH}_{4}$ retrievals from SWIR3 suffer from interferences with water vapor absorption. The observed correlated error patterns generally amount to a few tens ppb, which would jeopardize the usefulness of the $\mathrm{XCH}_{4}$ retrievals for inverse modeling of sources/sinks at the surface.

Acknowledgements. This research was funded by the European Space Agency (ESA) through the Consolidation of S5-SWIR requirements project: RfQ 3-13741/12/NL/CT/lf and by Deutsche Forschungsgemeinschaft (DFG) through the Emmy Noether Programme, grant BU2599/1-1 (RemoteC). The authors would like to thank Manfred Birk and Georg Wagner from DLR for helpful discussions concerning the application of high-resolution atmospheric transmission residuals recorded with ground-based FTIR spectrometers for the estimation of resulting retrieval biases of satellite sensors. The authors thank to I. Aben, Christian Frankenberg and one anonymous reviewer for their comments and suggestions. We also acknowledge the support by Deutsche Forschungsgemeinschaft and the Open Access Publishing Fund of Karlsruhe Institute of Technology.

The article processing charges for this open-access publication were covered by a Research

Centre of the Helmholtz Association.

Edited by: H. Worden

\section{References}

Basu, S., Guerlet, S., Butz, A., Houweling, S., Hasekamp, O., Aben, I., Krummel, P., Steele, P., Langenfelds, R., Torn, M., Biraud, S., Stephens, B., Andrews, A., and Worthy, D.: Global $\mathrm{CO}_{2}$ fluxes estimated from GOSAT retrievals of total column $\mathrm{CO}_{2}$, Atmos. Chem. Phys., 13, 8695-8717, doi:10.5194/acp-13-86952013, 2013.

Bergamaschi, P., Frankenberg, C., Meirink, J. F., Krol, M., Dentener, F., Wagner, T., Platt, U., Kaplan, J. O., Körner, S., Heimann, M., Dlugokencky, E. J., and Goede, A.: Satellite cartography of atmospheric methane from SCIAMACHY on board ENVISAT: 2. Evaluation based on inverse model simulations, J. Geophys. Res-Atmos., 112, D02304, doi:10.1029/2006JD007268, 2007.

Bergamaschi, P., Frankenberg, C., Meirink, J. F., Krol, M., Villani, M. G., Houweling, S., Dentener, F., Dlugokencky, E. J., Miller, J. B., Gatti, L. V., Engel, A., and Levin, I.: Inverse modeling of global and regional $\mathrm{CH}_{4}$ emissions using SCIAMACHY satellite retrievals, J. Geophys. Res., 114, 22301, doi:10.1029/2009JD012287, 2009.

Bovensmann, H., Burrows, J., Buchwitz, M., Frerick, J., Noël, S., Rozanov, V., Chance, K., and Goede, A.: SCIAMACHY: mission objectives and measurement modes, J. Atmos. Sci., 56, 127-150, 1999.

Brown, L., Sung, K., Benner, D., Devi, V., Boudon, V., Gabard, T., Wenger, C., Campargue, A., Leshchishina, O., Kassi, S., Mondelain, D., Wang, L., Daumont, L., Régalia, L., Rey, M., Thomas, X., Tyuterev, V. G., Lyulin, O., Nikitin, A., Niederer, H., Albert, S., Bauerecker, S., Quack, M., O’Brien, J., Gordon, I., Rothman, L., Sasada, H., Coustenis, A., Smith Jr., M. T. C., Wang, X.-G., Mantz, A., and Spickler, P.: Methane line parameters in the HITRAN2012 database, J. Quant. Spectrosc. Ra., 130, 201-219, doi:10.1016/j.jqsrt.2013.06.020, 2013.

Buchwitz, M., Reuter, M., Bovensmann, H., Pillai, D., Heymann, J., Schneising, O., Rozanov, V., Krings, T., Burrows, J. P., Boesch, H., Gerbig, C., Meijer, Y., and Löscher, A.: Carbon Monitoring Satellite (CarbonSat): assessment of atmospheric $\mathrm{CO}_{2}$ and $\mathrm{CH}_{4}$ retrieval errors by error parameterization, Atmos. Meas. Tech., 6, 3477-3500, doi:10.5194/amt-6-3477-2013, 2013.

Butz, A., Bösch, H., Camy-Peyret, C., Chipperfield, M. P., Dorf, M., Kreycy, S., Kritten, L., Prados-Román, C., Schwärzle, J., and Pfeilsticker, K.: Constraints on inorganic gaseous iodine in the tropical upper troposphere and stratosphere inferred from balloon-borne solar occultation observations, Atmos. Chem. Phys., 9, 7229-7242, doi:10.5194/acp-9-7229-2009, 2009.

Butz, A., Hasekamp, O. P., Frankenberg, C., Vidot, J., and Aben, I.: $\mathrm{CH}_{4}$ retrievals from space-based solar backscatter measurements: performance evaluation against simulated aerosol and cirrus loaded scenes, J. Geophys. Res., 115, 24302, doi:10.1029/2010JD014514, 2010.

Butz, A., Guerlet, S., Hasekamp, O., Schepers, D., Galli, A., Aben, I., Frankenberg, C., Hartmann, J.-M., Tran, H., Kuze, A., Keppel-Aleks, G., Toon, G., Wunch, D., Wennberg, P., Deutscher, N., Griffith, D., Macatangay, R., Messerschmidt, J., Notholt, J., and Warneke, T.: Toward accurate $\mathrm{CO}_{2}$ and $\mathrm{CH}_{4}$ observations from GOSAT, Geophys. Res. Lett., 38, L14812, doi:10.1029/2011GL047888, 2011.

Butz, A., Galli, A., Hasekamp, O., Landgraf, J., Tol, P., and Aben, I.: TROPOMI aboard Sentinel-5 Precursor: prospective performance of $\mathrm{CH}_{4}$ retrievals for aerosol and cirrus loaded atmospheres, Remote Sens. Environ., 120, 267-276, doi:10.1016/j.rse.2011.05.030, 2012.

Chevallier, F., Bréon, F.-M., and Rayner, P. J.: Contribution of the Orbiting Carbon Observatory to the estimation of $\mathrm{CO}_{2}$ sources and sinks: theoretical study in a variational data assimilation framework, J. Geophys. Res., 112, 9307, doi:10.1029/2006JD007375, 2007.

Frankenberg, C., Meirink, J. F., van Weele, M., Platt, U., and Wagner, T.: Assessing methane emissions from global space-borne observations, Science, 308, 1010-1014, doi:10.1126/science.1106644, 2005.

Frankenberg, C., Bergamaschi, P., Butz, A., Houweling, S., Meirink, J. F., Notholt, J., Petersen, A. K., Schrijver, H., Warneke, T., and Aben, I.: Tropical methane emissions: a revised view from SCIAMACHY onboard ENVISAT, Geophys Res. Lett., 35, L15811, doi:10.1029/2008GL034300, 2008a.

Frankenberg, C., Warneke, T., Butz, A., Aben, I., Hase, F., Spietz, P., and Brown, L. R.: Pressure broadening in the $2 \mathrm{v}_{3}$ band of methane and its implication on atmospheric retrievals, Atmos. Chem. Phys., 8, 5061-5075, doi:10.5194/acp-8-5061-2008, $2008 b$. 
Galli, A., Butz, A., Scheepmaker, R. A., Hasekamp, O., Landgraf, J., Tol, P., Wunch, D., Deutscher, N. M., Toon, G. C., Wennberg, P. O., Griffith, D. W. T., and Aben, I.: $\mathrm{CH}_{4}, \mathrm{CO}$, and $\mathrm{H}_{2} \mathrm{O}$ spectroscopy for the Sentinel-5 Precursor mission: an assessment with the Total Carbon Column Observing Network measurements, Atmos. Meas. Tech., 5, 1387-1398, doi:10.5194/amt-51387-2012, 2012.

Ghysels, M., Gomez, L., Cousin, J., Tran, H., Amarouche, N., Engel, A., Levin, I., and Durry, G.: Temperature dependences of air-broadening, air-narrowing and line-mixing coefficients of the methane $v_{3}$ R6 manifold lines - application to in-situ measurements of atmospheric methane, J. Quant. Spectrosc. Ra., 133, 206-216, doi:10.1016/j.jqsrt.2013.08.003, 2014.

Gisi, M., Hase, F., Dohe, S., Blumenstock, T., Simon, A., and Keens, A.: Gisi, M., Hase, F., Dohe, S., Blumenstock, T., Simon, A., and Keens, A.: $\mathrm{XCO}_{2}$-measurements with a tabletop FTS using solar absorption spectroscopy, Atmos. Meas. Tech., 5, 2969-2980, doi:10.5194/amt-5-2969-2012, 2012.

Guerlet, S., Butz, A., Schepers, D., Basu, S., Hasekamp, O. P., Kuze, A., Yokota, T., Blavier, J.-F., Deutscher, N. M., Griffith, D. W.-T., Hase, F., Kyro, E., Morino, I., Sherlock, V., Sussmann, R., Galli, A., and Aben, I.: Impact of aerosol and thin cirrus on retrieving and validating $\mathrm{XCO}_{2}$ from GOSAT shortwave infrared measurements, J. Geophys. Res.-Atmos., 118, 4887-4905, doi:10.1002/jgrd.50332, 2013.

Hansen, P. C.: Rank-Deficient and Discrete Ill-Posed Problems: Numerical Aspects of Linear Inversion, SIAM - Monographs on Mathematical Modeling and Computation 4, Chapter 5, Philadelphia, USA, 1998.

Ingmann, P., Veihelmann, B., Langen, J., Lamarre, D., Stark, H., and Courrèges-Lacoste, G. B.: Requirements for the GMES atmosphere service and ESA's implementation concept: Sentinels-4/-5 and-5p, Remote Sens. Environ., 120, 58-69, doi:10.1016/j.rse.2012.01.023, 2012.

Kirschke, S., Bousquet, P., Ciais, P., Saunois, M., Canadell, J. G., Dlugokencky, E. J., Bergam- aschi, P., Bergmann, D., Blake, D. R., Bruhwiler, L., Cameron-Smith, P., Castaldi, S., Chevallier, F., Feng, L., Fraser, A., Heimann, M., Hodson, E., L., Houweling, S., Josse, B., Fraser, P. J., Krummel, P. B., Lamarque, J.F., Langenfelds, R. L., Le Quere, C., Naik, V., O'Doherty, S., Palmer, P. I., Pison, I., Plummer, D., Poulter, B., Prinn, R. G., Rigby, M., Ringeval, B., Santini, M., Schmidt, M., Shindell, D. T., Simpson, I. J., Spahni, R., Steele, L. P., Strode, S. A., Sudo, K., Szopa, S., van der Werf, G. R., Voulgarakis, A., van Weele, M., Weiss, R. F., Williams, J. E., and Zeng, G.: Three decades of global methane sources and sinks, Nat. Geosci., 6, 813-823, doi:10.1038/ngeo1955, 2013.

Kuze, A., Suto, H., Nakajima, M., and Hamazaki, T.: Thermal and near infrared sensor for carbon observation Fourier-transform spectrometer on the greenhouse gases observing satellite for greenhouse gases monitoring, Appl. Optics, 48, 6716-6733, doi:10.1364/AO.48.006716, 2009.

Meirink, J. F., Bergamaschi, P., and Krol, M. C.: Fourdimensional variational data assimilation for inverse modelling of atmospheric methane emissions: method and comparison with synthesis inversion, Atmos. Chem. Phys., 8, 6341-6353, doi:10.5194/acp-8-6341-2008, 2008.

Miller, C. E., Crisp, D., DeCola, P. L., Olsen, S. C., Randerson, J. T., Michalak, A. M., Alkhaled, A., Rayner, P., Jacob, D. J., Sunthar- alingam, P., Jones, D. B. A., Denning, A. S., Nicholls, M. E., Doney, S. C., Pawson, S., Bösch, H., Connor, B. J., Fung, I. Y., O'Brien, D., Salawitch, R. J., Sander, S. P., Sen, B., Tans, P., Toon, G. C., Wennberg, P. O., Wofsy, S. C., Yung, Y. L., and Law, R. M.: Precision requirements for space-based $X_{\mathrm{CO}_{2}}$ data, J. Geophys. Res., 112, 10314, doi:10.1029/2006JD007659, 2007.

Nikitin, A., Lyulin, O., Mikhailenko, S., Perevalov, V., Filippov, N., Grigoriev, I., Morino, I., Yokota, T., Kumazawa, R., and Watanabe, T.: GOSAT-2009 methane spectral line list in the 5550$6236 \mathrm{~cm}^{-1}$ range, J. Quant. Spectrosc. Ra., 111, 2211-2224, doi:10.1016/j.jqsrt.2010.05.010, 2010.

Nikitin, A., Boudon, V., Wenger, C., Albert, S., Brown, L., Bauerecker, S., and Quack, M.: High resolution spectroscopy and first global analysis of the Tetradecad region of methane ${ }^{12} \mathrm{CH}_{4}$, Phys. Chem. Chem. Phys., 15, 10071-10093, doi:10.1039/C3CP50799H, 2013.

O’Dell, C. W., Connor, B., Bösch, H., O’Brien, D., Frankenberg, C., Castano, R., Christi, M., Eldering, D., Fisher, B., Gunson, M., McDuffie, J., Miller, C. E., Natraj, V., Oyafuso, F., Polonsky, I., Smyth, M., Taylor, T., Toon, G. C., Wennberg, P. O., and Wunch, D.: The ACOS $\mathrm{CO}_{2}$ retrieval algorithm - Part 1: Description and validation against synthetic observations, Atmos. Meas. Tech., 5, 99-121, doi:10.5194/amt-5-99-2012, 2012.

Oshchepkov, S., Bril, A., and Yokota, T.: PPDF-based method to account for atmospheric light scattering in observations of carbon dioxide from space, J. Geophys. Res., 113, 23210, doi:10.1029/2008JD010061, 2008.

Palmer, P. I., Feng, L., and Bösch, H.: Spatial resolution of tropical terrestrial $\mathrm{CO}_{2}$ fluxes inferred using space-borne column $\mathrm{CO}_{2}$ sampled in different earth orbits: the role of spatial error correlations, Atmos. Meas. Tech., 4, 1995-2006, doi:10.5194/amt-41995-2011, 2011.

Peters, W., Jacobson, A. R., Sweeney, C., Andrews, A. E., Conway, T. J., Masarie, K., Miller, J. B., Bruhwiler, L. M. P., Petron, G., Hirsch, A. I., Worthy, D. E. J., van der Werf, G. R., Randerson, J. T., Wennberg, P. O., Krol, M. C., and Tans, P. P.: An atmospheric perspective on North American Carbon Dioxide exchange: CarbonTracker, P. Natl. Acad. Sci. USA, 104, 1892518930, doi:10.1073/pnas.0708986104, 2007.

Reuter, M., Buchwitz, M., Schneising, O., Heymann, J., Bovensmann, H., and Burrows, J. P.: A method for improved SCIAMACHY $\mathrm{CO}_{2}$ retrieval in the presence of optically thin clouds, Atmos. Meas. Tech., 3, 209-232, doi:10.5194/amt-3-209-2010, 2010.

Rodgers, C.: Inverse Methods for Atmospheric Sounding: Theory and Practice, Series on Atmospheric Oceanic and Planetary Physics, vol. 2, World Scientific Publishing Company, Chapters 3 and 5, River Edge, NJ, USA, 2000.

Rothman, L. S., Gordon, I. E., Barbe, A., Benner, D. C., Bernath, P. F., Birk, M., Boudon, V., Brown, L. R., Campargue, A., Champion, J., Chance, K., Coudert, L. H., Dana, V., Devi, V. M., Fally, S., Flaud, J., Gamache, R. R., Goldman, A., Jacquemart, D., Kleiner, I., Lacome, N., Lafferty, W. J., Mandin, J., Massie, S. T., Mikhailenko, S. N., Miller, C. E., Moazzen-Ahmadi, N., Naumenko, O. V., Nikitin, A. V., Orphal, J., Perevalov, V. I., Perrin, A., Predoi-Cross, A., Rinsland, C. P., Rotger, M., Rotger, M., Šimecková, M., Smith, M. A. H., Sung, K., Tashkun, S. A., Tennyson, J., Toth, R. A., Vandaele, A. C., and Vander Auwera, J.: 
The HITRAN 2008 molecular spectroscopic database, J. Quant. Spectrosc. Radiat. Transfer, 110, 533-572, 2009.

Rothman, L. S., Gordon, I. E., Babikov, Y., Barbe, A., Chris Benner, D., Bernath, P. F., Birk, M., Bizzocchi, L., Boudon, V., Brown, L. R., Campargue, A., Chance, K., Cohen, E. A., Coudert, L. H., Devi, V. M., Drouin, B. J., Fayt, A., Flaud, J.-M., Gamache, R. R., Harrison, J. J., Hartmann, J.-M., Hill, C., Hodges, J. T., Jacquemart, D., Jolly, A., Lamouroux, J., Le Roy, R. J., Li, G., Long, D. A., Lyulin, O. M., Mackie, C. J., Massie, S. T., Mikhailenko, S., Müller, H. S. P., Naumenko, O. V., Nikitin, A. V., Orphal, J., Perevalov, V., Perrin, A., Polovtseva, E. R., Richard, C., Smith, M. A. H., Starikova, E., Sung, K., Tashkun, S., Tennyson, J., Toon, G. C., Tyuterev, Vl. G., and Wagner, G.: The HITRAN 2012 molecular spectroscopic database, J. Quant. Spectrosc. Ra., 130, 4-50, doi:10.1016/j.jqsrt.2013.07.002, 2013.

Scheepmaker, R. A., Frankenberg, C., Galli, A., Butz, A., Schrijver, H., Deutscher, N. M., Wunch, D., Warneke, T., Fally, S., and Aben, I.: Improved water vapour spectroscopy in the $4174-4300 \mathrm{~cm}^{-1}$ region and its impact on SCIAMACHY $\mathrm{HDO} / \mathrm{H}_{2} \mathrm{O}$ measurements, Atmos. Meas. Tech., 6, 879-894, doi:10.5194/amt-6-879-2013, 2013.

Schneising, O., Buchwitz, M., Burrows, J. P., Bovensmann, H., Bergamaschi, P., and Peters, W.: Three years of greenhouse gas column-averaged dry air mole fractions retrieved from satellite - Part 2: Methane, Atmos. Chem. Phys., 9, 443-465, doi:10.5194/acp-9-443-2009, 2009.

Schrijver, H., Gloudemans, A. M. S., Frankenberg, C., and Aben, I.: Water vapour total columns from SCIAMACHY spectra in the $2.36 \mu \mathrm{m}$ window, Atmos. Meas. Tech., 2, 561-571, doi:10.5194/amt-2-561-2009, 2009.

Stier, P., Feichter, J., Kinne, S., Kloster, S., Vignati, E., Wilson, J., Ganzeveld, L., Tegen, I., Werner, M., Balkanski, Y., Schulz, M., Boucher, O., Minikin, A., and Petzold, A.: The aerosol-climate model ECHAM5-HAM, Atmos. Chem. Phys., 5, 1125-1156, doi:10.5194/acp-5-1125-2005, 2005.
Streets, D. G., Canty, t., Carmichael, G. R., de Foy, B., Dickerson, R. R., Duncan, B. R., Ed- wards, D. P., Haynes, J. A., Henze, D. A., Houyoux, M. R., Jacob, D. J., Krotkov, N. A., Lamsal, L. N., Liu, Y., Lu, Z., Martin, R. V., Pfister, G. G., Pinder, R. W., Salawitch, R. J., and Wecht, K. J.: Emissions estimation from satellite retrievals: a review of current capability, Atmos. Environ., 77, 1011-1042, doi:10.1016/j.atmosenv.2013.05.051, 2013.

Thompson, D. R., Benner, D. C., Brown, L. R., Crisp, D., Devi, V. M., Jiang, Y., Natraj, V., Oyafuso, F., Sung, K., Wunch, D., Castano, R., and Miller, C. E.: Atmospheric validation of high accuracy $\mathrm{CO}_{2}$ absorption coefficients for the OCO-2 mission, J. Quant. Spectrosc. Ra., 113, 2265-2276, doi:10.1016/j.jqsrt.2012.05.021, 2012.

Tran, H., Hartmann, J., Toon, G., Brown, L., Frankenberg, C., Warneke, T., Spietz, P., and Hase, F.: The $2 v_{3}$ band of $\mathrm{CH}_{4}$ revisited with line mixing: consequences for spectroscopy and atmospheric retrievals at $1.67 \mu \mathrm{m}$, J. Quant. Spectrosc. Ra., 111, 1344-1356, doi:10.1016/j.jqsrt.2010.02.015, 2010.

Tyuterev, V., Tashkun, S., Rey, M., Kochanov, R., Nikitin, A., and Delahaye, T.: Accurate spectroscopic models for methane polyads derived from a potential energy surface using high-order contact transformations, J. Phys. Chem. A, 117, 13779-13805, doi:10.1021/jp408116j, 2013.

Veefkind, J. P., Aben, I., McMullan, K., Förster, H., de Vries, J., Otter, G., Claas, J., Eskes, H. J., de Haan, J. F., Kleipool, Q., van Weele, M., Hasekamp, O., Hoogeveen, R., Landgraf, J., Snel, R., Tol, P., Ingmann, P., Voors, R., Kruizinga, B., Vink, R., Visser, H., and Levelt, P. F.: TROPOMI on the ESA Sentinel-5 Precursor: a GMES mission for global observations of the atmospheric composition for climate, air quality and ozone layer applications, Remote Sens. Environ., 120, 70-83, doi:10.1016/j.rse.2011.09.027, 2012. 